\section{Awareness under anaesthesia}

EDITOR, - I believe that Di Brighouse and John Norman should have put more emphasis on the treatment of patients who have been aware while under anaesthesia.' At the second world congress on anaesthetic awareness, held in Atlanta in May, three speakers presented studies on patients who had been aware while under anaesthesia. My paper looked at the treatment of 32 patients who had been aware. I have shown in this group that an early explanation with counselling by an anaesthetist experienced in helping such patients reduces the risk of post-traumatic stress disorder developing. If such a disorder has developed an explanation with counselling can reduce its severity and duration.

I suggest that every anaesthetic department should have an anaesthetist prepared to help patients who have been aware, particularly if another anaesthetic is necessary, as this provides an additional stressor. Clearly with major stress reactions psychological help is needed, and psychiatrists and psychologists who are prepared to help should be identified. Lastly, an anaesthetist who has a patient who says that he or she was aware may find this stressful and also need help.

J M CUNDY

Lewisham Hospital, London SE13 6LH

1 Brighouse D, Norman J. To wake in fright. BMF 1992;304:1327. (23 May.)

EDIToR,-Di Brighouse and John Norman's editorial on awareness under anaesthesia is the latest in a series reviewing the problem and, like its predecessors, comes to no useful conclusion. ${ }^{1}$ Apart from cases due to malfunction of equipment, the problem is due to the deliberate administration of inadequate doses of anaesthetic drugs. This practice is possible only when high doses of neuromuscular blocking agents are used to abolish movement of the patient, which in turn abolishes much of the diagnostic information needed to assess the state of anaesthesia.

Techniques involving inadequate doses of anaesthetic drugs additionally expose patients to the risks of excessive response of the autonomic nervous system to surgery. Brighouse and Norman make no attempt to justify such techniques other than by saying: "It has become fashionable to reduce the inhaled concentration of gaseous and volatile anaesthetics to minimise their other effects."

There are no objective studies showing that such techniques bring any benefit to the patient whatsoever. Neuromuscular blocking drugs were originally introduced to anaesthesia at a time when general anaesthetic drugs were highly unsatisfactory and specifically to solve the problem of access to the abdomen for major surgery. Since then anaesthetic drugs have become much more effective, with a better profile of action permitting effective anaesthesia and rapid recovery, and the need for neuromuscular blocking drugs has radically diminished. Many of these changes seem to have escaped the notice of anaesthetists in Britain, where this problem is most acute.

In patients undergoing surgery after life threatening trauma, when the dose of anaesthetic drugs is kept to a minimum, there is a straightforward choice between the risk of awareness and the risk of potentially lethal cardiovascular depression. In the case of anaesthesia for caesarean section, while there are grounds for believing that reducing the doses of anaesthetic drugs may help the fetus, no recent cooperative studies between anaesthetists and paediatricians have shed any light on this issue.

In summary, anaesthetists in Britain persist in using the techniques of profound neuromuscular block with inadequate doses of anaesthetic drugs despite evidence of substantive morbidity and no evidence of benefit.

Division of Anaesthesia,

W G ANDERSON

Royal Infirmary,

1 Brighouse D, Norman J. To wake in fright. BMF 1992;304 1327-8. (23 May.)

EDITOR, - Di Brighouse and John Norman remind readers that there is no totally reliable monitor of intraoperative awareness. ' Two aspects, however, deserve comment.

Firstly, the word "awareness" is used to indicate "a period when patients are awake during surgery" or the "conscious postoperative recall for events occurring during surgery." This can be confusing to non-anaesthetists.

Secondly, we disagree with the authors' assessment of the isolated forearm technique. We admit that this technique correlates relatively poorly with clinical signs of light anaesthesia, but this is because clinical signs are unreliable. Likewise, because of the amnesic effects of the anaesthetic, the technique cannot be used to predict who will have recall. If a patient moves a hand in response to an intraoperative command or indicates the presence or absence of pain during surgery by appropriate hand squeezing ${ }^{3}$ surely this conveys a clear message, irrespective of any clinical signs, regarding the level of conscious processing at that time.

Intraoperative use of the isolated forearm technique shows the unreliability of clinical signs in predicting intraoperative awareness, the high frequency of such awareness with certain anaesthetic techniques, but the rarity of spontaneous postoperative recall. ${ }^{5}$ Over many years of personal clinical use there has been little evidence of postoperative recall in patients who did not respond to intraoperative commands. Exceptions have been one case in the early days of the technique, ${ }^{6}$ one case of failure of the tourniquet, and one patient who made a conscious decision to ignore the commands "because they kept interrupting my lovely dreams."

Brighouse and Norman base their assessment of the isolated forearm technique on a preliminary abstract ${ }^{7}$ (to our knowledge, no follow up paper of the complete study has ever been published). The methodology and conclusions of that study were severely criticised at the time. ${ }^{89}$ The results showed that no patient responded to commands before surgery started, and, although no data are presented, there is an implication that once surgery started clinical signs indicated that anaesthesia was adequate but surgery proved impossible because of "purposeful movements of the isolated arm." To deal with this the authors deflated the tourniquet to paralyse the arm. We believe that an arm trying to interfere with surgery is a valid indicator of light anaesthesia irrespective of the clinical signs. As regards the other methods proposed for predicting anaesthetic awareness, the isolated forearm technique is the "nearest we have to a 'gold standard" against which to evaluate these."10

IAN F RUSSELL

artment of Anaesthesia,

Hull Royal Infirmary, Hull HU3 2JZ

Department of Psychology,

MICHAEL WANG

University of Hull, Hull HU6 7RX

I Brighouse D, Norman J. To wake in fright. BMf 1992;304: 1327-8. (23 May.)

2 Ghonheim MM, Block RI. The word "awareness": its ambiguity and confusing use in anesthesia literature on memory. Anesthesiology 1990;73:193.

3 Russell IF. Midazolam-alfentanil: an anesthetic? In: Sebel PS, ed. The second international symposium on memory and awareness in anesthesia. New Jersey: Simon and Schuster (in press)

4 Russell IF. Comparison of wakefulness with two anaesthetic regimens. Total IV $v$ balanced anaesthesia. $B r$ f Anaesth 1986;58:965-8.

5 Russell IF. Conscious awareness during general anaesthesia relevance of autonomic signs and isolated arm movements as guides to depth of anaesthesia. In: Jones JG, ed. Anaesthesia, Bailliere's clinical anaesthesiology. Vol 3. Depth of anaesthesio. London: Baillière-Tindall, 1989:511-32.

Russell IF. Auditory perception under anaesthesia. Anaesthesia 1979;34:211.

7 Breckenridge J, Aitkenhead AR. Isolated forearm technique fo detecting wakefulness during general anaesthesia. Br $\mathcal{A}$ Anaesth 1981;53:665-6.

8 Wilson ME. Detection of wakefulness during general anaesthesia. Br F Anaesth 1981;53:1234.

9 Russell IF. Wakefulness and general anaesthesia. Br $\mathcal{F}$ Anaest 1982;54:573.

10 Jessop J, Jones JG. Conscious awareness during general anaesthesia - what are we attempting to monitor? $\mathrm{Br} \mathcal{f}$ Anaesth 1991;66:635-7.

\section{Risks associated with assisted conception}

EDITOR, - M G R Hull and colleagues state that the objective of their study was "to provide reliable prognostic information for couples seeking assisted conception." There seems little doubt from the pregnancy and live birth rates reported that their centre produces impressive results. Such figures will give great encouragement to both subfertile couples and their doctors. But the authors make the very mistakes for which they criticise others, presenting a selective picture of the outcome. By omitting even to mention the possible hazards they run the risk of leaving their medical colleagues and the public seriously underinformed. I write both as a doctor and as a consumer (with my wife) of in vitro fertilisation, and my experience of assisted conception serves to underline my point.

My previously fit wife underwent her firstapparently routine - cycle of in vitro fertilisation treatment at a reputable joint private and NHS unit in London. She became pregnant with twins. Although not apparent at the time, infection was introduced, presumably at egg collection, and she went on to develop ascites and peritonitis and had to have an emergency laparotomy. Postoperatively, she was nursed in the intensive care unit, where she was found to have multiple pulmonary emboli and later developed a perforation of the bowel followed by faecal peritonitis requiring another laparotomy. After the second operation she developed septic shock and required ventilation and inotropic drugs for 10 days. Her recovery was complicated by a bowel fistula, which healed spontaneously. My wife left hospital, no longer pregnant, after three months, a month of which was spent in intensive care.

I realise that such an experience is extremely rare 